\title{
Mesangial Matrix Assessment
}

National Cancer Institute

\section{Source}

National Cancer Institute. Mesangial Matrix Assessment. NCI Thesaurus. Code C135471.

An evaluation of the presence or degree of mesangial matrix present in a sample. 